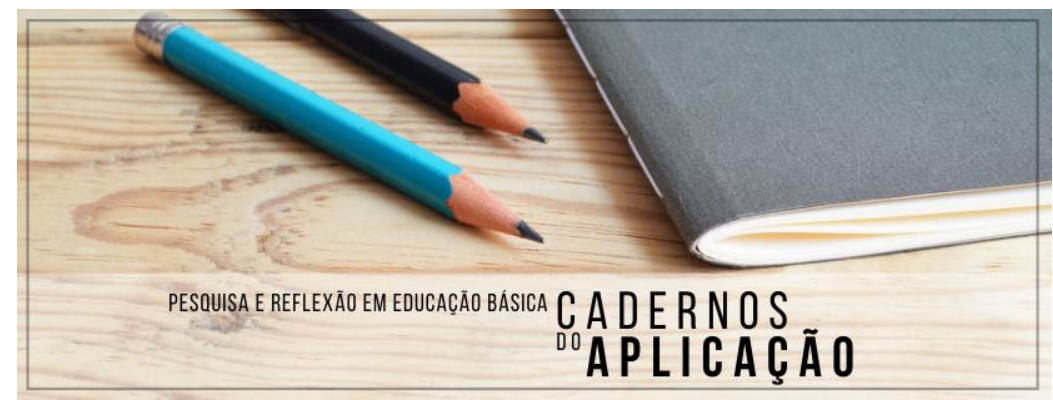

Cadernos do Aplicação

https://seer.ufrgs.br/CadernosdoAplicacao

Publicação Ahead of Print

ISSN 2595-4377 (online)

Porto Alegre | jul-dez. 2021 | v.34 | n.2

\title{
Um estudo sobre a construção da identidade docente
}

Clériston Jesus da Cruz ${ }^{1}$

Resumo: $O$ presente artigo tem por objetivo discutir alguns dos fatores que auxiliam na construção da identidade docente. Tais fatores se encontram nos trilhos sócio-históricos, profissionais e cognitivos da sociedade, formando e reformando a práxis educativa num processo de constante transformação e evolução. Para mais, o artigo busca compreender como os diferentes fatores interferem nas identidades dos profissionais que se encontram nas salas de aulas, de tal modo que suas práticas sejam alteradas ao decorrer de suas vidas profissionais. Como embasamento teórico, foram utilizados os estudos de Freire (2011), Ciampa (1984), Dubar (1997), Hall (2005), Bauman (2005), entre outros, que dizem respeito à construção da identidade. Logo, conclui-se que a cultura, a moral e a ética, estabelecidas em uma sociedade, na qual o sujeito está inserido, inferem nas identidades dos indivíduos. De igual modo, a globalização em comunhão com a economia, também contribuem para esse formar e reformar da identidade docente.

Palavras-chave: Identidade. Formação docente. Praxis

\section{A study on the construction of the teacher identity}

\begin{abstract}
This article aims to discuss some of the factors that help in the construction of the teaching identity. Such factors are found in the socio-historical, professional and cognitive tracks of society, forming and reforming educational praxis in a process of constant transformation and evolution. Furthermore, the article seeks to understand how the different factors interfere in the identities of the professionals who are in the classrooms, in such a way that their practices are changed during their professional lives. As a theoretical basis, the studies of Freire (2011), Ciampa (1984), Dubar (1997), Hall (2005), Bauman (2005), among others, which concern the construction of identity, were used. Therefore, it is concluded that culture, morals and ethics, established in a society, in which the subject is inserted, infer the identities of individuals. Likewise, globalization in communion with the economy, also contributes to this formation and reform of the teaching identity.
\end{abstract}

Keywords: Identity. Teacher training. Praxis

\footnotetext{
${ }^{1}$ Mestrando em Estudo de Linguagens pela Universidade do Estado da Bahia (UNEB - Campus I). E-mail: cleriston.cruz@hotmail.com. ORCID iD: https://orcid.org/0000-0002-4197-6531
} 


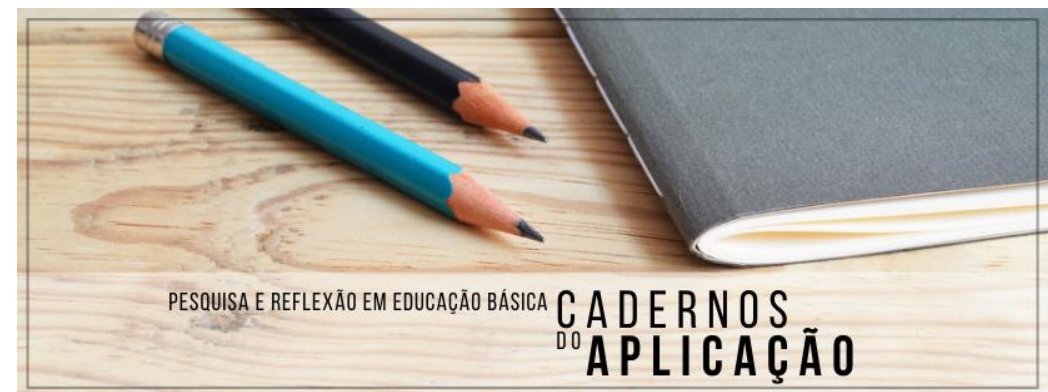

Cadernos do Aplicação

https://seer.ufrgs.br/CadernosdoAplicacao

Publicação Ahead of Print

ISSN 2595-4377 (online)

Porto Alegre | jul-dez. 2021 | v.34 | n.2

\title{
Un estudio sobre la construcción de la identidad de professores
}

\begin{abstract}
Resumen: Este artículo tiene como objetivo discutir algunos de los factores que ayudan en la construcción de la identidad docente. Dichos factores se encuentran en las trayectorias sociohistóricas, profesionales y cognitivas de la sociedad, formando y reformando la praxis educativa en un proceso de constante transformación y evolución. Además, el artículo busca comprender cómo los diferentes factores interfieren en las identidades de los profesionales que se encuentran en las aulas, de tal manera que sus prácticas se alteran durante su vida profesional. Como base teórica se utilizaron los estudios de Freire (2011), Ciampa (1984), Dubar (1997), Hall (2005), Bauman (2005), entre otros, que se refieren a la construcción de la identidad. Por tanto, se concluye que la cultura, la moral y la ética, establecidas en una sociedad, en la que se inserta el sujeto, infieren las identidades de los individuos. Asimismo, la globalización en comunión con la economía, también contribuyen a esta formación y reforma de la identidad docente.
\end{abstract}

Palabras clave: Identidad. Formación de profesores. Praxis

\section{Introdução}

Identidade é movimento, é desenvolvimento do concreto.

Identidade é metamorfose.

É sermos o Um e um Outro, para que cheguemos a ser Um, numa infindável transformação (CIAMPA, 1987, p. 74).

Pensar em identidade é adentrar em um campo de batalha. Assim, entende o sociólogo Zygmunt Bauman (2005, p. 83) ao destacar a relevante e recorrente discussão sobre este conceito. Certamente, não se pode ignorá-lo, visto que é intrínseco à experiência humana. Nessa perspectiva, observa-se que em sua trajetória existencial o ser humano comumente depara-se com a pergunta: “Quem é você?” ou “Quem sou?”. Aparentemente é fácil respondê-la, haja vista ser algo relacionado a si mesmo, no entanto, ao vasculhar o baú das lembranças nota-se a dificuldade em se autodefinir.

Partindo desse pressuposto, o presente artigo tem por objetivo discutir alguns dos fatores que auxiliam na construção da identidade docente. Tais fatores se encontram nos trilhos sóciohistóricos, profissionais e cognitivos da sociedade, formando e reformando a práxis educativa num processo de constante transformação e evolução. Para mais, o artigo busca compreender como os diferentes fatores interferem na identidade dos profissionais que se encontram nas 


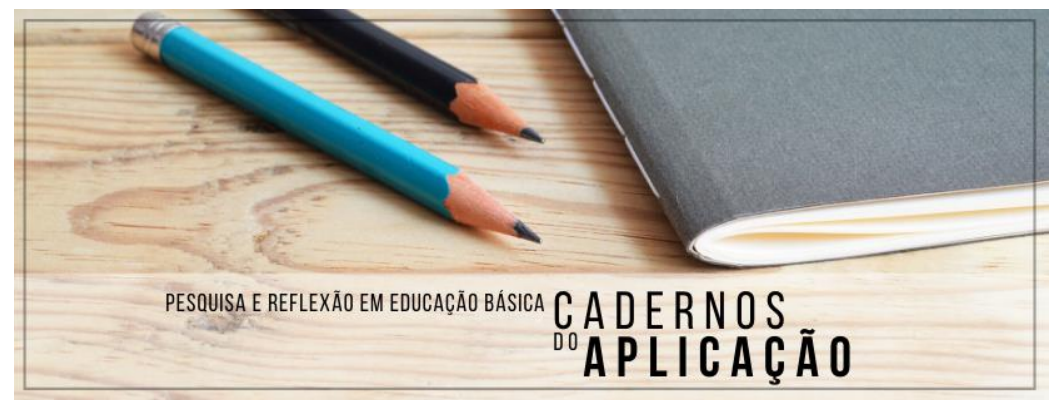

Cadernos do Aplicação

https://seer.ufrgs.br/CadernosdoAplicacao

Publicação Ahead of Print

ISSN 2595-4377 (online)

Porto Alegre | jul-dez. 2021 | v.34 | n.2

salas de aulas, de tal modo que suas práticas sejam alteradas ao decorrer de suas vidas profissionais.

Em razão do caráter subjetivo do tema a ser discutido, foi empregada neste trabalho a abordagem qualitativa que se volve com empatia aos motivos, às intenções, aspirações, crenças, valores, atitudes, aos projetos dos atores, a partir dos quais as ações, as estruturas e as relações tornam-se significativas, ou seja, preocupa-se com um nível de realidade que não pode ser quantificado. Consequentemente, o trabalho que se alicerça em uma abordagem qualitativa não pretende o alcance da verdade como o que é certo ou errado.

Ademais, a técnica utilizada para coleta de dados é a documentação indireta, por apresentar uma pesquisa bibliográfica, desenvolvida com base em material já elaborado - livros, artigos científicos, dissertações ou teses do meio impresso ou digital.

Como embasamento teórico foram utilizados os estudos de Faria e Souza (2011), Bohnen (2011), Pereira (1994), Freire (2011), Jesus (2004), Tozetto e Gomes (2013), bem como, os estudos de Ciampa (1984), Dubar (1997), Hall (2005) e Bauman (2005), que dizem respeito à construção da identidade. Em síntese, o artigo é um convite para penetrar o "campo de batalha", que, segundo Bauman (2005, p. 83-84), é o lar natural da identidade.

\section{Pensando a construção de uma identidade docente}

[...] quem forma se forma e re-forma ao formar, e quem é formado forma-se e forma ao ser formado" (FREIRE, 2011, p. 25).

Há palavras que são dotadas de uma polivalência de sentidos, sendo originalmente polissêmicas. Entre essas, o termo identidade se destaca, uma vez que, segundo Hall (2005, p. 8), o seu conceito é demasiado complexo, pouco desenvolvido e pouco compreendido na ciência social contemporânea. Logo, torna-se ímprobo apresentar informações conclusivas.

Hall (2005), ao estudar as identidades culturais na perspectiva da pós-modernidade, aponta e distingue três concepções de identidade, tridimensionalmente opostas: Sujeito do Iluminismo - que se fundamentava na crença do indivíduo unificado, centrado, cuja identidade com ele nascia e se desenvolvia ao longo de sua existência, ainda que permanecesse, substancialmente o mesmo. Entretanto, Hall (2005, p. 13) considera tal perspectiva uma 
Cadernos do Aplicação

https://seer.ufrgs.br/CadernosdoAplicacao

Publicação Ahead of Print

ISSN 2595-4377 (online)

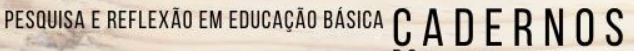

${ }^{0} A P L I C A C ̧ A ̃ O$

Porto Alegre | jul-dez. 2021 | v.34 | n.2

fantasia por estarmos imersos em uma multiplicidade de identidades com as quais possamos nos identificar.

A segunda concepção apresentada é a visão do Sujeito Sociológico. Contrapondo-se à visão individualista supramencionada, este conceito refletia a complexidade do mundo moderno, compreendendo a formação da identidade a partir da interação entre o eu e a sociedade. Nesse sentido, o sujeito ainda é o centro, porém, forma-se e se modifica por intermédio de um incessante diálogo com os sistemas culturais que nos rodeiam (HALL, 2005, p. 11). A terceira e última concepção denomina-se Sujeito Pós-moderno. Aqui, a identidade é definida historicamente e não biologicamente. Desse modo, o sujeito assume identidades diferentes em diferentes momentos (HALL, 2005, p. 13).

A respeito dos muitos conceitos de identidade, Ciampa (1987), que aborda a identidade como categoria da Psicologia Social, a entende como metamorfose, tendo como característica o movimento. Na perspectiva da Sociologia, mas com foco na pós-modernidade, Bauman (2005) define identidade como algo inconcluso, mutável, ou melhor, um processo de construção do sujeito historicamente situado. Assim, ponderar acerca de construção identitária é pensar em experimentação infindável.

Claude Dubar, sociólogo francês, resume a composição das formas identitárias a partir do cruzamento de dois processos: o relacional - a identidade através da visão do outro que, por conseguinte, assume um caráter mais objetivo, e o biográfico - diz respeito à identidade para si, considerando a história e os projetos da pessoa, em um viés subjetivo. Logo, Dubar (1997, p. 104) afirma que a "identidade nunca é dada, é sempre construída”. Sobre essa afirmação, Faria e Souza (2011, p. 37) reconhecem uma aproximação entre Dubar (1997) e Ciampa (1984), quando ambos afirmam que a identidade se constrói na e pela atividade.

Bohnen (2006), ao fazer um estudo sobre a identidade do professor, aponta outras concepções, como por exemplo a de Moita Lopes (1998), que propõe a tese de as identidades sociais serem construídas através de nossas práticas discursivas em relação ao outro. À vista disso, não se constrói a identidade sem se considerar o discurso. Bohnen (2006) cita também Rajagopalan (1998), para quem a identidade do ser humano se constitui na língua e através dela. $\mathrm{Na}$ concepção deste último, discutir identidade pressupõe pleitear sobre linguagem. 
Hall (2005), por exemplo, expõe que em sentido oposto ao conceito cartesiano de sujeito - "Penso, logo existo" - Freud argumenta que as identidades são formadas com base em processos psíquicos e simbólicos do inconsciente. Destarte, Hall (2005) conclui que a identidade é, com efeito, algo formado no decurso da existência humana por meio de procedimentos inconscientes e não algo inato. Assim sendo, ela permanece sempre inacabada, em processo contínuo. Por conseguinte, a identidade emerge menos da plenitude que já está dentro dos indivíduos e mais de uma falta de inteireza que é preenchida a partir do exterior, pelas formas através das quais imagina-se ser visto por outros.

No tocante a apresentação de conceitos de identidade, importa ressaltar, assim como fizera Faria e Souza (2011), que a intenção não foi consumir o tema da identidade, identificando e apresentando todos os autores que o têm abordado. Em contrapartida, teve-se como finalidade apontar alguns teóricos, levando em conta "a pertinência de seus trabalhos, no que concerne ao investimento e consistência ou repercussão dos mesmos" (FARIA; SOUZA, 2011, p.38).

Desde os estágios iniciais de sua formação, o futuro docente é acometido por um estereótipo de professor utópico, ou seja, o profissional idealizado pela educação dos sonhos. Professor, conhecedor de todas as teorias, grande intelectual da literatura e das ciências, que ama explicar, amante da didática e dos planejamentos, porta-se com um verdadeiro gentleman ou uma virtuosa lady perante os seus alunos e ainda é sinônimo de carinho e amizade. Será que de fato esse modelo de professor algum dia será alcançado? Ao pensarmos na identidade como algo também particular ao indivíduo, teremos, por conseguinte, uma homogeneidade docente e de práxis?

Para responder aos questionamentos anteriores, pensa-se inicialmente no inacabamento do indivíduo. O ser humano está sempre em desenvolvimento e a consciência de que se é inacabado leva os indivíduos a uma constante retrospecção e uma futuridade acerca de sua função na vida. Isso torna-se interessante e vantajoso para a profissão de docente, pois no momento que se entende que o ser humano não é predeterminado, que é um sujeito em modificação, o professor consequentemente compreende que sua práxis não deve obedecer a um modelo imutável, mas que pode se adaptar a contextos vários com a finalidade de proporcionar uma aprendizagem mais eficaz para os seus discentes. 


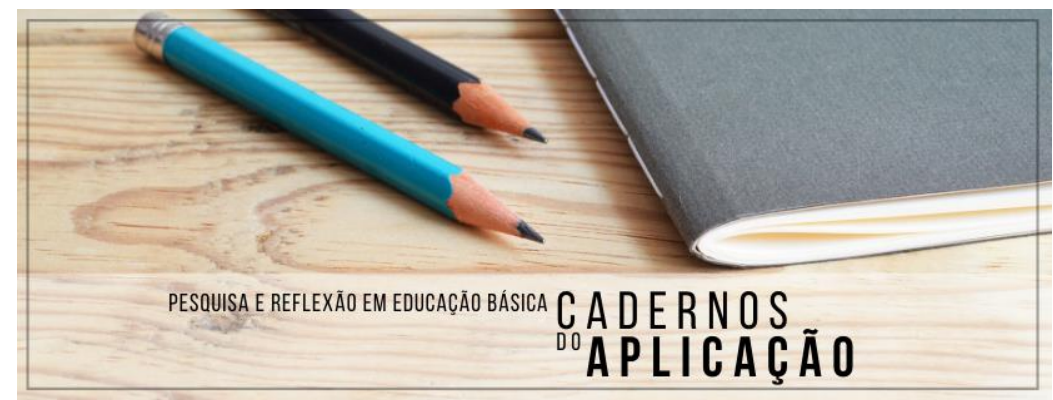

Cadernos do Aplicação

https://seer.ufrgs.br/CadernosdoAplicacao

Publicação Ahead of Print

ISSN 2595-4377 (online)

Porto Alegre | jul-dez. 2021 | v.34 | n.2

De mais a mais, Freire (2011, p. 52) disserta sobre a necessidade de ser inacabado:

Gosto de ser homem, de ser gente, porque não está dado como certo, inequívoco, irrevogável que sou ou serei decente, que testemunharei sempre gestos puros [...] Gosto de ser homem, de ser gente, porque sei que minha passagem pelo mundo não é predeterminada, preestabelecida. Que meu "destino" não é um dado mas algo que precisa ser feito e de cuja responsabilidade não posso me eximir. Gosto de ser gente porque a História em que me faço com os outros e de cuja feitura tomo parte é um tempo de possibilidades e não de determinismo. Daí que insista tanto na problematização do futuro e recuse sua inexorabilidade.

Após o entendimento de que o ser humano é incompleto, considera-se saber que a formação de sua identidade é contínua. Assim, é nas experiências adquiridas ao longo da vida que há mudanças e/ou ratificações das identidades já construídas. É interessante observar que, os movimentos que se dão nas alterações identitárias provocam ocorrentes crises. As crises, por sua vez, se dariam no embate entre aquilo que já se tem concretizado/definido em oposição ao novo. No caso do profissional de educação, as crises de identidade podem surgir por fatores diversificados: quando se percebe que toda a teoria estudada em sua formação não é suficiente para guiar a sua prática; quando conhece a realidade escolar, em especial a pública; quando não se alcança o respeito desejado dos discentes; a má valorização econômica e, em alguns casos, a social; longas jornadas de trabalho que se expandem ao lar; problemas pessoais que interferem na atuação profissional; dentre outros.

Outro ponto sobre os estudos identitários é que em tempos de globalização vive-se um período no qual o indivíduo outrora estável, definido em aspectos como nacionalidade, raça, gênero ou sexualidade, deu lugar ao homem de identidade fragmentada. Acerca disso, Bohnen (2011, p. 25) acrescenta que "os preceitos e limites rígidos que norteavam o comportamento das pessoas, dando-lhe uma aparente estabilidade, se liquefazem gerando uma sensação de nãopertencimento, de chão movediço".

Hall (2005) entende que tais transformações estão alterando as identidades pessoais, influenciando a ideia de sujeito integrado: 


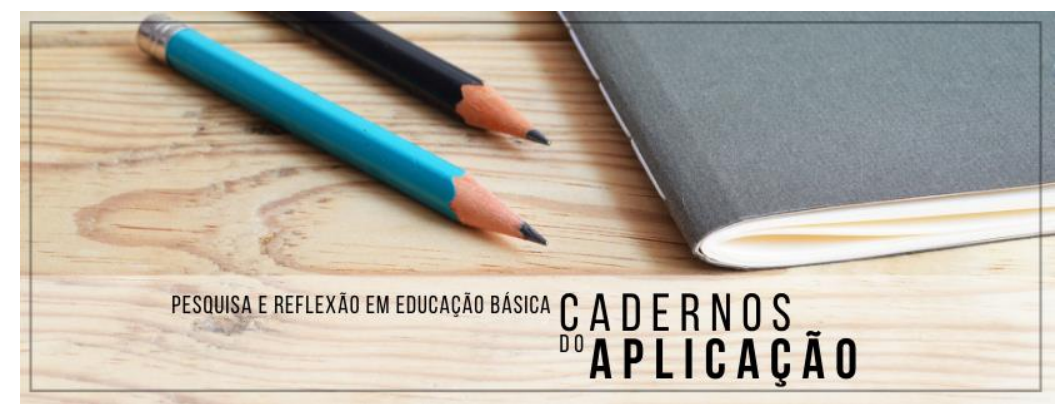

Cadernos do Aplicação

https://seer.ufrgs.br/CadernosdoAplicacao

Publicação Ahead of Print

ISSN 2595-4377 (online)

Porto Alegre | jul-dez. 2021 | v.34 | n.2

Esta perda de um "sentido de si" estável é chamada, algumas vezes, de duplo deslocamento ou descentração do sujeito. Esse duplo deslocamento descentração dos indivíduos tanto de seu lugar no mundo social e cultural quanto de si mesmos - resulta em "crise de identidade". (HALL, 2005, p. 9)

A crise de identidade é vista, segundo Hall (2005), como um amplo processo de mudança que desloca as estruturas responsáveis por propiciar um sentimento de segurança e consistência aos indivíduos em seus papéis sociais, abalando, por conseguinte, os quadros de referência que davam aos indivíduos uma ancoragem estável no mundo social.

Jesus (2004), ao discorrer sobre a Desmotivação e crise de identidade na profissão docente, expõe a teoria de Lévy-Leboyer (1984) sobre a crise das motivações, ressaltando que, atualmente, as pessoas apresentam cada vez menor motivação intrínseca para as atividades profissionais (JESUS, 2004, p. 193).

Jesus (2004, p. 193), com base em Lévy-Leboyer (1984), considera as elevadas taxas de desemprego um dos diversos fatores que contribuem para a diminuição da motivação profissional dos sujeitos, ocasionando um aumento da percentagem de trabalhadores insatisfeitos que permanecem na profissão exercida. Destaca-se também o declínio e a perda de prestígio da imagem social dos professores, verificando-se um baixo estatuto à profissão docente, inclusive pelos próprios professores (JESUS, 2004, p. 194).

Em razão da mudança no perfil do professor - de mero transmissor de conhecimentos a facilitador da aprendizagem dos alunos - houve, consequentemente, alterações nos procedimentos do professor nas atividades desenvolvidas na sala de aula. Além disso, de acordo com Jesus (2004, p. 197), ao docente foram atribuídas novas funções que transcendem este espaço, confrontando-os com novos deveres, exigências e funções.

As novas responsabilidades atribuídas ao professor representam uma sobrecarga de trabalho, pois, para além do trabalho na sala de aula, o professor deve ainda organizar actividades extra-curriculares: preparar aulas, corrigir e avaliar os trabalhos dos alunos, receber os pais ou encarregados de educação, participar em reuniões de professores, ocupar-se de problemas administrativos da escola, etc. Face a esta diversidade de tarefas, os professores têm dificuldade em definir e delimitar os objectivos e prioridades na sua actividade profissional, tanto mais porque não participaram na concepção das novas funções. Esta situação tem sido traduzida pela noção de "crise de identidade" (JESUS, 2004, p. 197). 
Jesus (2004) assinala que esta "crise" é resultado do paradoxo entre o "eu ideal" - aquilo que os docentes desejam ser ou foram instruídos para efetuar - e o "eu real" - aquilo que eles têm que ser e fazer quotidianamente nas escolas.

Uma vez entendida a ocorrência da crise identitária e que esta não se restringe ao professor já formado, pensa-se nesse momento nos professores em formação. Em grande parte, os discentes em formação não possuem experiência prévia com a sala de aula, logo, ao se depararem com esses espaços, são envolvidos por sentimentos que geralmente os desmotivam. Essa desmotivação coloca em xeque o que é ser professor e se realmente esta é a profissão adequada a seguir. É nesse momento que se inicia o confrontamento entre o que os estudantes estão aprendendo nas licenciaturas e o que está sendo vivenciado nas salas de aulas. Então, se instaura uma crise que os leva a refletir sobre o papel que este sujeito em formação tem perante a educação e a sociedade. Sociedade esta que o forma e que agora necessita de suas habilidades para intermediar a formação de outrem. Eis, a maior responsabilidade do professor.

Vivemos em sociedades modernas, cuja característica são as constantes transformações, de modo rápido e permanente, em contraposição às sociedades "tradicionais" (HALL, 2005, p. 14). Juntamente com as mudanças sociais, o ser humano defronta-se com "uma multiplicidade desconcertante e cambiante de identidades possíveis" (HALL, 2005, p. 13), pois as identidades surgem do sentimento de "pertencimento" às culturas étnicas, raciais, linguísticas, religiosas e, acima de tudo, nacionais. Em suma, o sujeito pós-moderno, fragmentado, está imerso em identidades culturais.

Partindo da perspectiva de Hall (2005), a identidade cultural particular se refere à identidade nacional, visto que no mundo moderno "as culturas nacionais em que nascemos se constituem em uma das principais fontes de identidade cultural" (HALL, 2005, p. 47).

Acerca dessa questão, surge a seguinte indagação levantada por Hall (2005): A identidade nacional seria uma identidade unificadora - uma identidade que anula e subordina a diferença cultural? Hall (2005) apresenta uma resposta, a saber:

Em vez de pensar as culturas nacionais como unificadas, deveríamos pensálas como constituindo um dispositivo discursivo que representa a diferença como unidade ou identidade. Elas são atravessadas por profundas divisões e diferenças internas, sendo "unificadas" apenas através do exercício de diferentes formas de poder cultural... Uma forma de unificá-las tem sido a de representá-las como a expressão da cultura subjacente de "um único povo" (HALL, 2005, p. 61-62). 


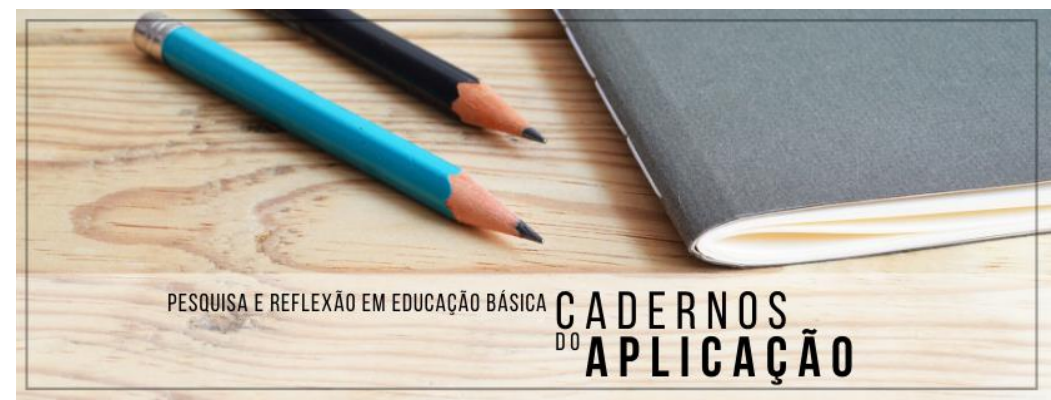

Cadernos do Aplicação https://seer.ufrgs.br/CadernosdoAplicacao

Publicação Ahead of Print

ISSN 2595-4377 (online)

Porto Alegre | jul-dez. 2021 | v.34 | n.2

A partir do viés de Hall (2005) compreende-se que uma cultura nacional não é um simples ponto de lealdade, união e identificação simbólica. Efetivamente, a crença de uma identidade unificada desde o nascimento até a morte se deve à cômoda história que os sujeitos criam acerca de si mesmos, ou seja, uma confortadora "narrativa do eu" (HALL, 2005, p. 13). Além disso, como salienta Bauman (2005, p. 12), em uma "sociedade que tornou incertas e transitórias as identidades sociais, culturais e sexuais, qualquer tentativa de solidificar o que se tornou líquido levaria, inevitavelmente, o pensamento crítico a um beco sem saída".

Nesse sentido, ao entender que o docente pertence a uma modernidade líquida que faz de sua identidade elemento heterogêneo, pode-se reparar que a prática similarmente sofrerá modificações, principalmente na aquisição de experiências. Dessa maneira, a prática docente deve ser guiada pela ética, no sentido que comungamos com Platão, que sugere a ética como conduta do bem ${ }^{2}$. Logo, o professor deve planejar suas aulas de modo a ser justo com todos que compõem o seu público, evitando diferenciar ou igualar os discentes. Outrossim, a prática docente está sempre alvo de interferência por estar sendo aplicada em sociedades globalizadas, em que os fluxos de informações são imprevisíveis. A globalização apressa o mundo para que ele mude, e em resposta, às caracterizações das nações, ou seja, as identidades nacionais tendem a ser alteradas.

O conceito de sujeito e, consequentemente, de identidade experimentaram diversas alterações ao longo da história, mormente no momento atual, "em que adventos como a globalização imprimem uma nova dimensão temporal e espacial na vida dos sujeitos" (FARIA e SOUZA, 2011, p. 38). Nesse cenário, Hall (2005) reconhece o impacto causado pela globalização na identidade cultural, cabendo ainda as palavras de Bauman (2005, p. 100):

Ocorrem as mudanças e os deslocamentos aparentemente aleatórios, fortuitos e totalmente imprevisíveis daquilo que, por falta de um nome mais preciso, chamamos de "forças da globalização". Elas transformam a ponto de tornarem irreconhecíveis, e sem aviso, as paisagens e perfis urbanos a nós familiares em que costumávamos lançar as âncoras de uma segurança duradoura e confiável.

\footnotetext{
${ }^{2}$ Para entender as conceituações que a ética recebe, e sua relação com a felicidade, ver a obra Ética e Felicidade: a aceitação da verdade como caminho para encontrar o sentido da vida (2012) do autor Roberto Patrus.
} 


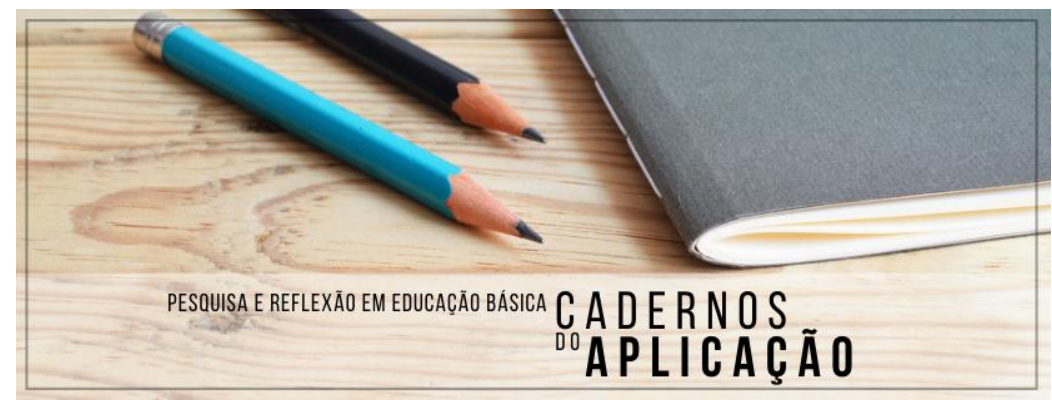

Cadernos do Aplicação

https://seer.ufrgs.br/CadernosdoAplicacao

Publicação Ahead of Print

ISSN 2595-4377 (online)

Porto Alegre | jul-dez. 2021 | v.34 | n.2

Como postulado anteriormente, as identidades culturais nacionais estão vivenciando "um complexo de processos e forças de mudança, que, por conveniência, pode ser sintetizado sob o termo globalização" (HALL, 2005, p. 67). Diante disso, Hall (2005), referindo-se ao pensamento de Anthony McGrew (1992), focaliza a globalização como:

[...] processos, atuantes numa escala global, que atravessam fronteiras nacionais, integrando e conectando comunidades e organizações em novas combinações de espaço-tempo, tornando o mundo, em realidade e em experiência, mais interconectado [...]. Essas novas características temporais e espaciais, que resultam na compressão de distâncias e de escalas temporais, estão entre os aspectos mais importantes da globalização a ter efeito sobre as identidades culturais (HALL, 2005, p. 67-68).

Portanto, é válido salientar que à medida que as relações do indivíduo com a sociedade tornam-se intermediadas pelo mercado global - de estilos, lugares e imagens, bem como pelos sistemas de comunicação interconectados - em maior velocidade as identidades se desvinculam. Em vista disso, o sujeito em sociedade depara-se com uma gama de díspares identidades, produzindo um efeito do que Hall chama de "supermercado cultural", dentre as quais deve-se realizar a escolha (HALL, 2005).

É a partir dessas escolhas identitárias, que são proporcionadas pela cultura, é que o professor se qualifica profissionalmente e humanamente. Por exemplo, quando o docente decide ser um pesquisador, o conhecimento que suas pesquisas propiciam interfere fortemente na sua identidade. Portanto, ser pesquisador é o que dá base à construção da identidade docente, pois no desejo de sempre saber mais, de procurar atualizar-se e de perquirir significações, o docente tem as suas verdades postas em dúvida, requerendo assim mais pesquisas e consequentemente agregações de saberes que podem ou não melhorar sua prática educativa.

Paulo Freire (2011), compara a prática educativo-crítica ao ato de cozinhar. A partir da prática de cozinhar o principiante vai sendo preparado, ratificando alguns saberes, retificando outros, confirmando, modificando e ampliando-os (FREIRE, 2011, p. 23-24). Da mesma maneira é a práxis docente, um constante aprender por meio da ação-reflexão-ação.

Práxis, segundo Pereira (1994), constitui-se na prática aprofundada por uma meditação e reflexão. É a ação com sentido humano, "projetada, refletida, consciente, transformadora do natural, do humano e do social" (PEREIRA, 1994, p.77). Nesse sentido, Pereira (1994) 


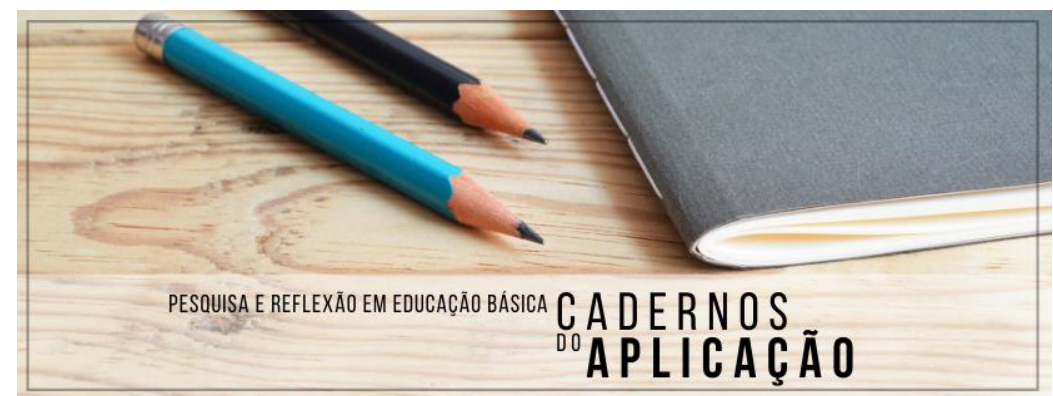

Cadernos do Aplicação

https://seer.ufrgs.br/CadernosdoAplicacao

Publicação Ahead of Print

ISSN 2595-4377 (online)

Porto Alegre | jul-dez. 2021 | v.34 | n.2

complementa que a teoria deve existir no desenvolvimento de composição da práxis, devido a ação do humano ser intrinsecamente cultural em contraposição a do animal. Assim, por ser uma ação gerada na cultura, teoria e prática não podem ser desassociadas, uma vez que é impossível ao homem engendrar a ação cultural se fundamentando no nada.

Pereira (1994, p. 80) ainda acrescenta:

Quando acentuamos ou separamos a prática em detrimento da teoria, caímos no praticismo, na visão pragmática ou utilitária da ação humana. Um praticismo (acento exagerado da prática) que igualmente estabelece a oposição ou cisão entre teoria e prática e só vê a teoria no seu lado negativo de "contemplação inútil", reduzindo o prático ao utilitário, dissolvendo o teórico no útil. Aliás, creio eu, esta pode ser uma atitude inclusive "fascista", porque rompe com a crença de que o homem na sua atividade possa crescer, amadurecer, a partir de sua prática refletida, teorizada.

É reconhecível que o ato de ensinar exige estudar teorias e entendê-las, posto que a função da atividade teórica é proporcionar perspectivas de análise, tendo em vista a apreensão dos contextos históricos, sociais, culturais, nos quais se dão as atividades docentes, para neles intervir, transformando-os (TOZETTO; GOMES, 2013). Outrossim, são as teorias que sustentam as ações, tornando-as coerentes. Entretanto, vale destacar que a construção do profissional de licenciatura não ocorre pelo mero conglomerado de conhecimentos ou técnicas, mas por meio de uma ação concreta, intencional e consciente. (TOZETTO e GOMES, 2013).

Diante das atuações na área da docência, sobretudo nos primórdios da caminhada, é comumente proferida a seguinte expressão: "Vejo que a prática se faz em sala de aula". A esse respeito, Bohnen (2011, p. 69) indaga: "e a teoria que se aprende durante a graduação não auxilia essa prática?”. Isto posto, a autora, traz a concepção de Jarmendia (2003), ao recordarse da recorrente frustração dos professores principiantes, "relacionado à sua formação, uma vez que os conhecimentos práticos e teóricos a que tiveram acesso não os preparam suficientemente para encarar os desafios cotidianos da prática docente" (BOHNEN, 2011, p. 69). Acerca dessa questão, cabem as palavras de Tozetto e Gomes (2013, p. 660): 


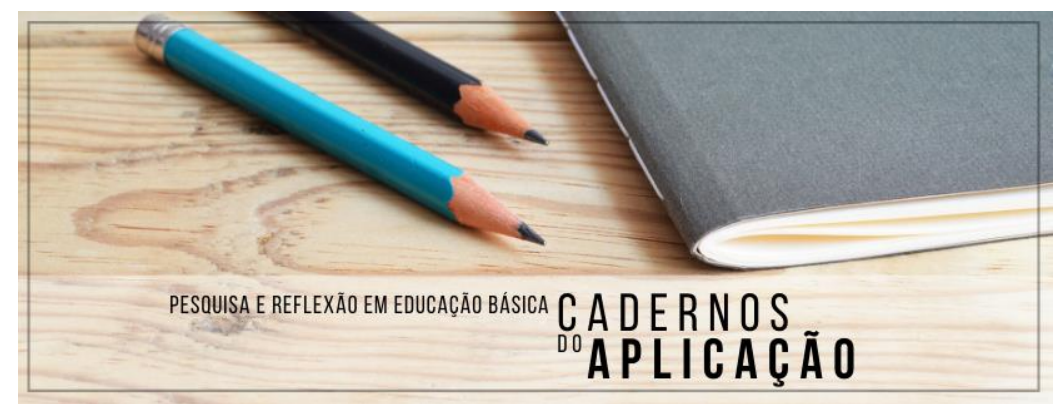

Cadernos do Aplicação

https://seer.ufrgs.br/CadernosdoAplicacao

Publicação Ahead of Print

ISSN 2595-4377 (online)

Porto Alegre | jul-dez. 2021 | v.34 | n.2

A teoria está sempre fundamentando e se interligando com a ação prática do sujeito e não vem de fora para dentro, ela nasce das relações que estabeleço com a realidade que vivo. É assim que se criam as relações, se estuda uma teoria e aí constrói-se uma prática que está intimamente ligada aos aspectos teóricos. A teoria é interiorizada e reelaborada para posteriormente ser operacionalizada na prática, ela nasce da contemplação da ação prática, é compreendida, apropriada e idealizada, para depois se constituir em ação real com a finalidade de transformação do mundo social e do homem.

No processo de construção da identidade docente se deve levar em consideração o dinamismo entre o fazer e o pensar sobre o fazer. Portanto, na formação permanente dos professores, o momento fundamental é o da reflexão crítica sobre a prática, dado que "é pensando criticamente a prática de hoje ou de ontem que se pode melhorar a próxima prática" (FREIRE, 2011, p. 40).

\section{Considerações finais}

A partir das noções de Hall (2005), Ciampa (1984), Bauman (2005), Dubar (1997) e dos outros estudiosos citados neste trabalho, compreende-se identidade como algo construído historicamente, que recebe influência dos aspectos sócio-históricos, profissionais e cognitivos da sociedade. Desse modo, como acentua Ciampa (1984, p. 64), identidade é "o resultado provisório da intersecção entre a história da pessoa, seu contexto histórico e social e seus projetos". Assim, o ser humano continua "buscando a 'identidade' e construindo biografias que tecem as diferentes partes de nossos 'eus' divididos numa unidade porque procuramos recapturar esse prazer fantasiado da plenitude" (HALL, 2005, p. 39).

O professor, sujeito que busca sua identidade e que colabora na formação da identidade do outro passa a vida atrás do seus "eus", construindo de maneiras diversificadas a sua práxis. Exemplo que confirma a mudança identitária docente é a transformação no que concerne à atuação do professor ao passar dos anos. O professor que outrora é considerado tirano ou inepto, pode posteriormente aos olhos da comunidade escolar ser visto como justo e sapiente. $\mathrm{O}$ professor, assim como qualquer profissional, tem a necessidade, se assim desejar, de reconstruir sua identidade se utilizando de si e do outro.

A título de conclusão, aponta-se que no desenrolar desta teia textual foram apresentados muitos fatores responsáveis por auxiliar a construção da identidade docente. Assim, notou-se 


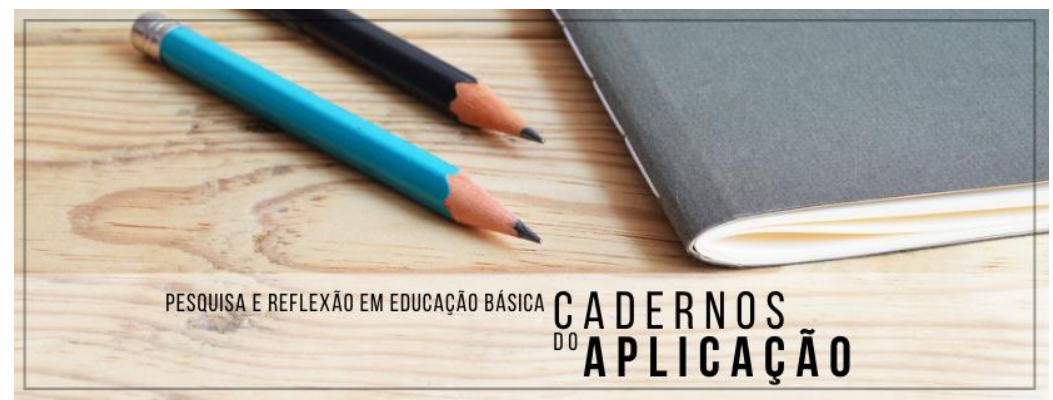

Cadernos do Aplicação https://seer.ufrgs.br/CadernosdoAplicacao

Publicação Ahead of Print

ISSN 2595-4377 (online)

Porto Alegre | jul-dez. 2021 | v.34 | n.2

que a cultura, a moral e a ética estabelecidas em uma sociedade na qual o sujeito está inserido interferem nas identidades dos indivíduos. De igual modo, a globalização em comunhão com a economia também contribui para esse formar e reformar identitário. Em síntese, os aspectos elencados encontram-se nos trilhos sócio-históricos, profissionais e cognitivos da sociedade, consubstanciando a práxis educativa.

\section{Referências}

BAUMAN, Zygmunt. Identidade: entrevista a Benedetto Vecchi. Rio de Janeiro: Zahar, 2005.

BOHNEN, Neusa Teresinha. A Jornada do Herói: A Narrativa autobiográfica na construção da identidade profissional do professor. (Mestrado em Letras) - Universidade Federal de Goiás, Goiânia, 2011.

CIAMPA, Antonio da Costa. Identidade. In: CODO, Wanderley; LANE, Silvia T. M. Psicologia social: o homem em movimento. São Paulo: Brasiliense, 1984, p. 58-75.

DUBAR, Claude. Para uma teoria sociológica da identidade. In: A socialização: construção das identidades sociais e profissionais. Porto: Porto Editora, 1997.

FARIA, Ederson de; SOUZA, Vera Lúcia Trevisan de. Sobre o conceito de identidade: apropriações em estudos sobre formação de professores. Revista Semestral da Associação Brasileira de Psicologia Escolar e Educacional, São Paulo, n.1, p.35-42,2011.

FREIRE, Paulo. Pedagogia da Autonomia: saberes necessários à prática educativa. São Paulo: Paz e Terra, 2011.

HALL, Stuart. A identidade na pós-modernidade. 10. ed. Rio de Janeiro: DP\&A, 2005.

JESUS, Saul Neves de. Desmotivação e crise de identidade na profissão docente. Katálysis. Florianópolis, $2004 . \quad$ Disponível em: <https://periodicos.ufsc.br/index.php/katalysis/article/view/6458/6317>. Acesso em: 23 mar. 2019.

PEREIRA, Otaviano. O que é teoria. São Paulo: Brasiliense, 1994.

TOZETTO, Susana Soares; GOMES, Thais de Sá. Formação inicial e a manifestação dos acadêmicos sobre a relação teoria prática. Perspectiva, Florianópolis, 2013. Disponível em: < https://periodicos.ufsc.br/index.php/perspectiva/article/view/2175-795X.2013v31n2p645>.

Acesso: 23 mar. 2019. 


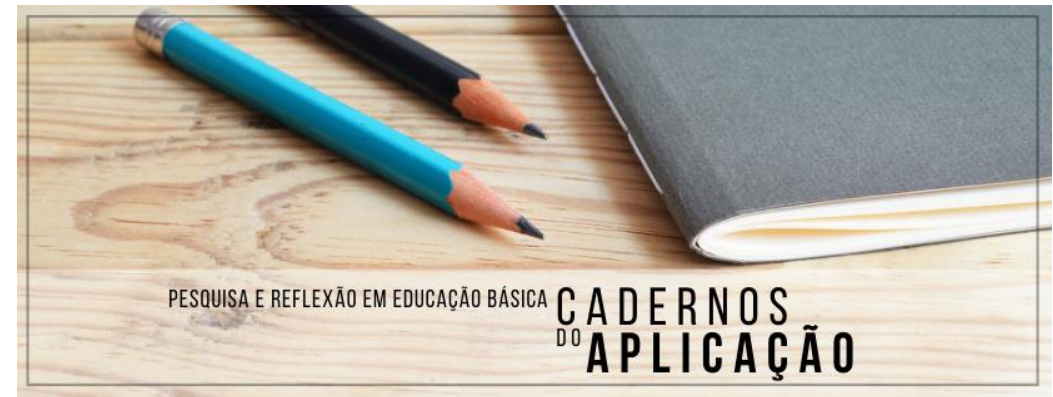

Cadernos do Aplicação

https://seer.ufrgs.br/CadernosdoAplicacao

Publicação Ahead of Print

ISSN 2595-4377 (online)

Porto Alegre | jul-dez. 2021 | v.34 | n.2

Data de submissão: 26/12/2020

Data de aceite: $29 / 03 / 2021$

DOI: https://doi.org/10.22456/2595-4377.110182 